\title{
Reasons and patterns of spatio-temporal variability of methane emission from the Mozhaysk reservoir in summer period
}

\author{
Viktor Lomov ${ }^{1 *}$, Maria Grechushnikova ${ }^{1,3}$, Vladimir Kazantsev ${ }^{2}$, and Irina Repina $^{2}$ \\ ${ }^{1}$ Moscow State University, Faculty of Geography, Hydrology Department, Moscow, Russia \\ ${ }^{2}$ Institute of Atmosphere Physics Russian Academy of Science, Moscow, Russia \\ ${ }^{3}$ Institute of Water Problems Russian Academy of Science, Moscow, Russia
}

\begin{abstract}
Anthropogenic reservoirs are not only sources of clean energy, flow regulators, recreational and food resources, but also sources of greenhouse gases such as methane. The studies presented in this work, done on a well-studied low-flowing valley reservoir mainly in the summer, when the greatest variability of methane fluxes was observe. Depending on synoptic conditions, the temporal variability of methane fluxes varies greatly. Methane fluxes increase during the summer period and huge methane emissions observed before the autumn mixing stage. Emissions can occur during the destruction of temperature stratification, as a result of stormy weather. With such emissions, methane fluxes into the atmosphere can reach about $20 \mathrm{mgC}^{*} \mathrm{~m}^{-2 *} \mathrm{~d}^{-1}$, which is higher than the emission during convection. Revealing the patterns of spatio-temporal distribution of methane fluxes will help to determine the contribution of water bodies (in particular reservoirs) to the total methane budget of the atmosphere more accurately.
\end{abstract}

\section{Introduction}

There is many discussions about global warming nowadays. The issue of anthropogenic contribution to this process is particularly acute. Methane is one of important greenhouse gases that has a high global warming potential of 72 (for 20 year interval) [1]. An important anthropogenic source is the reservoirs [2 - 4].

The main source of methane in the reservoir is the decomposition of organic matter $(\mathrm{OM})$ in bottom sediments. Important condition of this process is the absence of oxygen. The two main pathways for decomposing OM are acetate and hydrogenotrophic. Methane rises from the bottom layers of water to the surface and then enters the atmosphere by two main components of flux - bubbling and diffusion flux [5].Evaluation of methane emissions from water bodies, and especially from the reservoirs as an anthropogenic source of $\mathrm{CH}_{4}$, is a very important problem. According to different estimates, the methane flux from the world's reservoirs varies from 2 to 122 million tons per year, it is from 0.5 to $10 \%$ of its global emissions into the atmosphere [2-4]. The differences in the estimates are caused by

${ }^{*}$ Corresponding author: lomson620@mail.ru 
the number of reasons. The estimations are carried out by different parameterizations of the characteristics of the world's water bodies (average depth, flow rate, trophic status, geographical location, etc.). The authors define the groups of water bodies for classification in different ways. The estimates are carried out at different time intervals, and over time, the authors use the data on a larger number of studied reservoirs.In this work, more attention was paid to the studies of the variations of methane flux at a well-studied water body. This object is the Mozhaysk reservoir. Methane emissions have been monitored here since 2015. This article discusses the patterns of spatio-temporal variations in methane fluxes in the Mozhaisk reservoir in summer, and the factors that determine the structure of it. The study of these patterns may contribute to the refinement of global estimates of methane emissions from the reservoirs of the world in the future.

\section{Study site}

Mozhaisk reservoir was created in 1960 in the upper Moscow river. This is a typical valley type reservoir with low-flow regime (water exchange coefficient is 1.78 [6]). The main five observation stations ( $\mathrm{I}-\mathrm{V}$ ) over the flooded riverbed were chosen to study the spatial variability of methane fluxes in the reservoir. The location of this stations are shown at the scheme (Fig. 1).

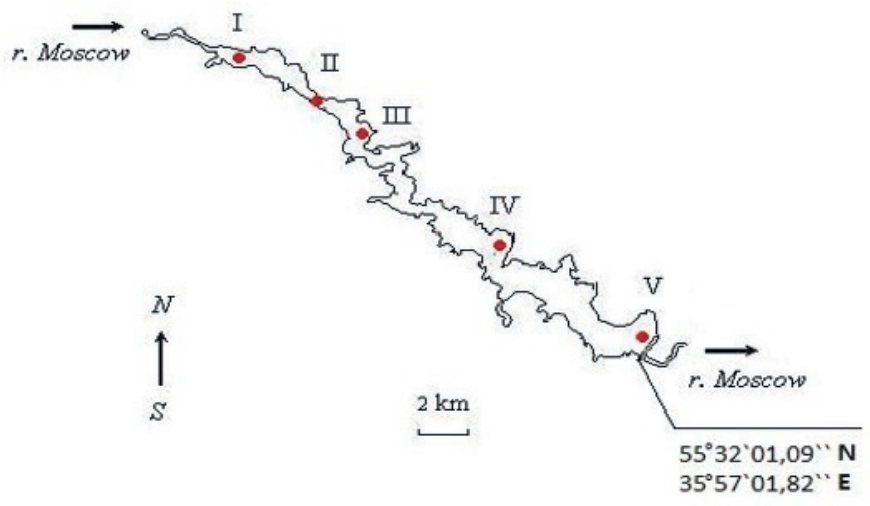

Fig. 1. Scheme of the Mozhaisk reservoir with the stations of measurements over the flooded riverbed.

The depths of stations from I to $\mathrm{V}$ are: $5,7,9,14$ and $20.5 \mathrm{~m}$, respectively (NWL). These stations are placed at a steady distance from each other along the length of the entire reservoir. Such placement allows us to study the distribution of different characteristics along the longitudinal profile from the upper reaches with the influence of the Moscow and Lusyanka rivers, to the transformation zone in the middle part of the reservoir and to the deeper part with a low-flow regime.

\section{Research methods}

All samples for determination methane concentrations were made by "headspace" method [7]. The samples with volume of $20 \mathrm{ml}$, obtained by shaking $40 \mathrm{ml}$ of water, were analyzed on a gas chromatograph "Khromatek-Crystal 5000.2" (CJSC Khromatek Yoshkar-Ola with a flame ionization detector). Determination of methane content in each sample was carried out in triple times. 
The "floating chambers" experiments for determining the total and diffusion flux of methane into the atmosphere [5] was carried out at reference stations during hydrological synchronous fieldwork, as well as during raid observations at station IV (Fig. 1). The exposure lasted for an hour. The diffusion flux was determined using a "diffusion chamber" [5] and calculated by the TBL [7] method.

The flux from bottom sediments was determined by the experiments with KuznetsovRomanenko bottom tubes. The sequence of the method is the following: the samples of bottom sediments were made by Ekman-Burge bottom grab, then they are taken without violating vertical structure. Undisturbed bottom sediments are placed in glass tubes and filled with bottom water. In parallel with the "sediment" tubes, "dry" tubes are filled without bottom sediments. The tubes are then refrigerated to create a temperature similar to in situ conditions. Their exposure lasts for two days, then the methane flux from the bottom sediments is calculated by the difference in methane concentration in the "sediment" and "dry" tubes. The "dry" tube needs to consider the formation of methane in the bottom water.

\section{Results}

Based on the results of this hydrological fieldworks during the summer period, a distribution of methane fluxes was obtained at the boundaries "bottom sediments - water" and "water - atmosphere" (Fig. 2 and Fig. 3).

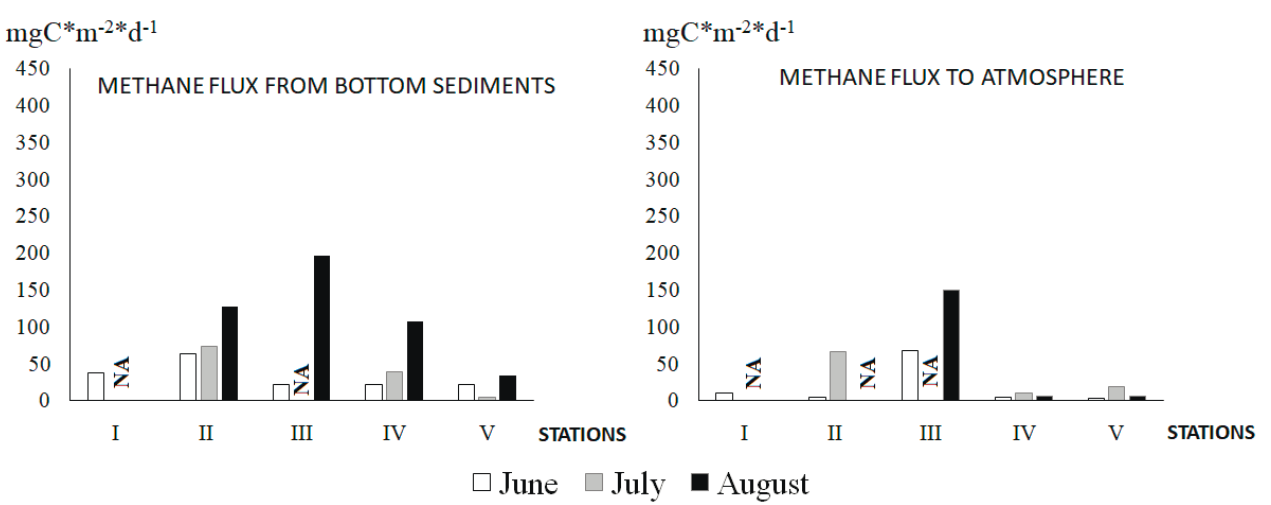

Fig. 2. Spatio-temporal variability of methane fluxes at the main stations for the summer period of 2018.

There was an increase in methane flux from bottom sediments and its flux into the atmosphere from June to August in 2018 (Fig. 2). The largest flux for the entire summer period is observed at station III in the middle part of the reservoir in August: $196 \mathrm{mgC}^{*} \mathrm{~m}^{-}$ $2 * \mathrm{~d}^{-1}$. At other stations, methane flux from sediments is also significant.

The flux of methane to the atmosphere in 2018 did not exceed the flux from bottom sediments at most measurement stations. At station III, in August, the highest flux into the atmosphere was observed, equal to $149 \mathrm{mgC}^{*} \mathrm{~m}^{-2 *} \mathrm{~d}^{-1}$. Significant methane emissions observed at station III in June $\left(67.5 \mathrm{mgC}^{*} \mathrm{~m}^{-2 *} \mathrm{~d}^{-1}\right)$ and at station II, more shallow (65.1

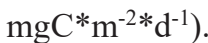

In 2019, the methane flux from bottom sediments did not increase so intensely during the summer period, and increase was observed only at two high depth stations IV and V (Fig. 3). At station IV, the maximum was observed in July at $43.0 \mathrm{mgC}^{*} \mathrm{~m}^{-2} * \mathrm{~d}^{-1}$. The largest flux at the "water-bottom sediment" boundary in the summer of 2019 was observed in August at station V $\left(174 \mathrm{mgC}^{*} \mathrm{~m}^{-2 *} \mathrm{~d}^{-1}\right)$. In June, the methane flux at this station is lower. 
Large methane fluxes from bottom sediments were also observed at station III with a maximum in July of $159 \mathrm{mgC}^{*} \mathrm{~m}^{-2 *} \mathrm{~d}^{-1}$.

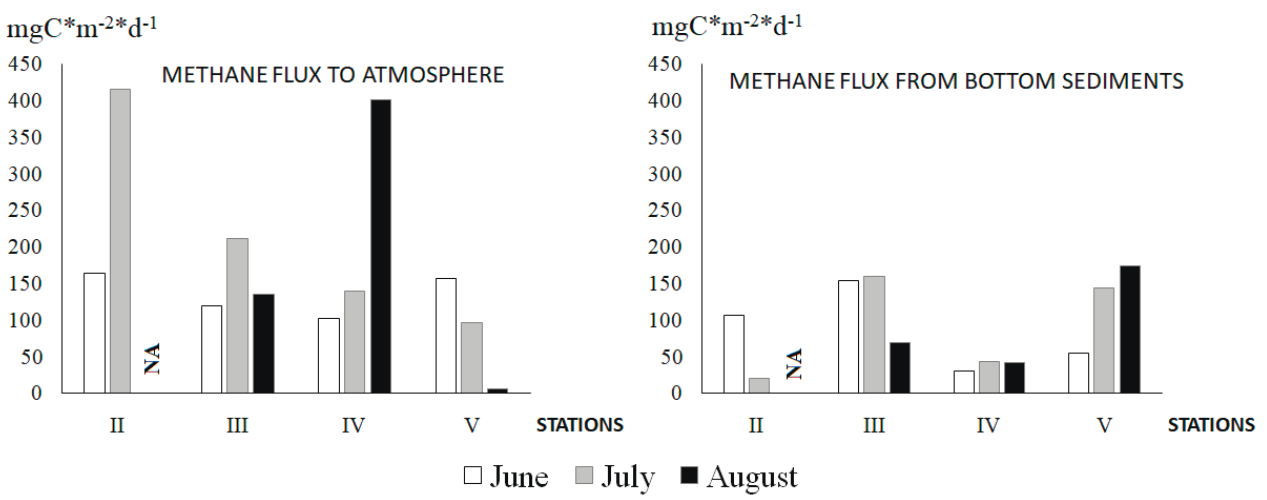

Fig. 3. Spatio-temporal variability of methane fluxes at the main stations for the summer period of 2019.

The flux of methane to the atmosphere was two times higher than the values of 2018 at many stations in the summer of 2019 (Fig. 3). The increase of flux during the summer period is observed only at stations II and IV, where the flux into atmosphere increased from 163 to $415 \mathrm{mgC}^{*} \mathrm{~m}^{-2 *} \mathrm{~d}^{-1}$ and from 101.3 to $400 \mathrm{mgC}^{*} \mathrm{~m}^{-2 *} \mathrm{~d}^{-1}$, respectively. The value observed in July at station II $\left(415 \mathrm{mgC}^{*} \mathrm{~m}^{-2 *} \mathrm{~d}^{-1}\right)$ is the largest methane flux over a 5 year observation period. At station III, the maximum flux of methane into the atmosphere was observed in July $\left(211 \mathrm{mgC}^{*} \mathrm{~m}^{-2 *} \mathrm{~d}^{-1}\right)$. At the deepest station $\mathrm{V}$, a decrease in methane flux over the summer period from 156 to $6.30 \mathrm{mgC}^{*} \mathrm{~m}^{-2 *} \mathrm{~d}^{-1}$ is observed.

More frequent measurements of methane fluxes into the atmosphere were carried out at station IV during the summer period for subsequent assessment of its global emissions (Fig. 4).

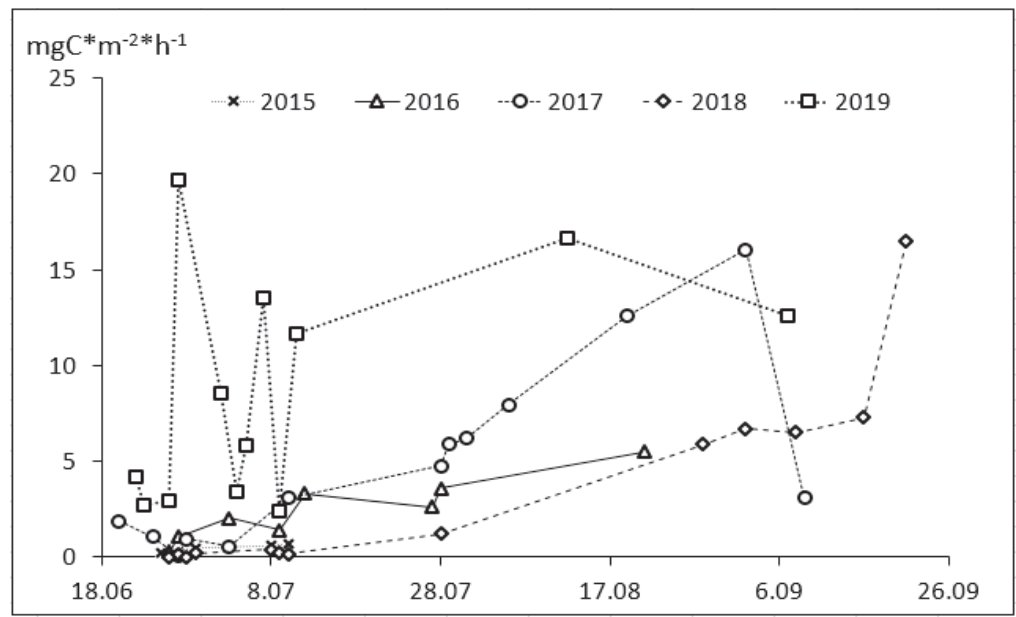

Fig. 4. Variation of methane flux into the atmosphere during the summer at Observation Station IV.

Fig. 4 shows, that the methane flux at the "water - atmosphere" boundary increase during the summer period. The highest emission value is observed in the period before the beginning of autumn convection stage. This is clearly seen in 2017 and 2018. The maximum value of the flux in 2017 is $16.1 \mathrm{mgC}^{*} \mathrm{~m}^{-2 *} \mathrm{~h}^{-1}$, in $2018: 16.5 \mathrm{mgC}^{*} \mathrm{~m}^{-2 *} \mathrm{~h}^{-1}$. The 
most special year from the general regularity is 2019. The maximum methane flux was observed on June 27, and its value was $19.7 \mathrm{mgC}^{*} \mathrm{~m}^{-2} * \mathrm{~h}^{-1}$.

\section{Discussion}

As the results of 2018 show, during the entire summer period, a gradual accumulation of methane occurred in the reservoir. Therefore, there was an increase in its fluxes from June to August. This can be explain by the presence in the reservoir of density stratification. High temperature gradient in metalimnion was observed throughout the summer. According to the data obtained, methane begins to accumulate at the bottom layers of water at oxygen concentrations of less than $1 \mathrm{mg}^{*} \mathrm{~L}^{-1}$. At the water layers closer to the reservoir's surface methane is being oxidized because of the high concentration of dissolved $\mathrm{O}_{2}$.

The best conditions for the formation of methane in the thickness of the bottom sediments are the depth of the station sufficient to establish stratification, but not too deep for a sedimentation of OM to the bottom. The described optimal conditions correspond to station III (depth is $9 \mathrm{~m}$ ). Therefore, here the highest values of the methane flux from the bottom are observed in 2018. The methane fluxes in the shallow-water zone of the reservoir are lower than in the middle zone of the reservoir due to a high oxygen concentration throughout the water column $\left(6-10 \mathrm{mg}^{*} \mathrm{~L}^{-1}\right)$ this year. A lot of $\mathrm{O}_{2}$ does not allow methane to accumulate in bottom layers. In addition, in this segment of the reservoir the amount of $\mathrm{OM}$ entering the bottom is not high. Methane output from the bottom in a deeper near-dam area is limited by a lower rate of OM intake and low water temperatures.

Some percentage of the methane diffusion flux coming from bottom sediments to the surface of the water is oxidized by methanotrophs. However, the bubble component makes a greater contribution to the total emission. According to the results, the share of the bubble flux in the total methane emission into the atmosphere can reach 97\%. Density stratification slows down the bubble flux. Therefore, the proportion of bubbles that dissolve in the water column increases. This part of the bubble flux does not reach the atmosphere due to oxidation. With less pronounced stratification, methane bubbles will more intensively reach the water surface.

This may explain the large difference in the ratio of methane flux from sediments to its flow into the atmosphere in 2018 and 2019. The tube method, which was used to determine the flux of methane from the sediments, underestimates the values of the bubble component of the flux. Some part of the methane bubbles during the experiment may be lost. In this regard, in 2019 there was an excess of methane flux into the atmosphere over the flux from bottom sediments. This is especially noticeable in August, when a significant methane flow and a high proportion of the bubble component have place. In 2018, an excess of methane flux into the atmosphere over the flux from bottom sediments was not observed due to the stable density stratification. The rate of dissolution of bubbles in water column and the oxidation of methane under such conditions is very high, so the understatement of the bubble flux does not affect so clearly.

According to the results of observations at station IV, a variation of the methane flux into the atmosphere has a general regularity for 2015 - 2018 years (Fig. 4). The methane flux is low at the beginning of summer, since the anoxic zone in hypolimnion just began to form. Flux values increase gradually by August with a slow extenuation of temperature stratification, as in 2017, or increase sharply, with the rapid destruction of stratification due to strong wind-wave exposure, as in 2018. In 2019, there were several significant peak in methane flux into the atmosphere (June 27 is the highest value of the flux of $19.7 \mathrm{mgC}^{*} \mathrm{~m}^{-}$ $2 * \mathrm{~h}^{-1}$, July 7 and 11 ). It was caused by to storm events at this time (wind gusts reached 20 $\mathrm{m}^{*} \mathrm{~s}^{-1}$ ). Such winds destroyed the temperature stratification, and methane accumulated in the hypolimnion from middle of May began to actively reach the atmosphere. No 
significant stratification was observed in the reservoir in last part of summer period, and the methane flux in the rest of the summer was steady.

\section{Conclusion}

Methane fluxes at the "bottom sediments - water" and "water - atmosphere" interfaces are complex and multifactorial processes. A detailed study of the spatial and temporal distribution of methane fluxes on the Mozhaisk reservoir for 5 years makes it possible to better understand the features of the formation of methane in bottom sediments, its release to the surface of the water, and its release into the atmosphere processes. The most interesting period to study is the summer season. A large variety of methane fluxes were observed this time. The amplitude of the flux and its variation during the summer period directly depend on the prevailing meteorological situation on the reservoir. Synoptic conditions determine the stability of density stratification, the intensity of wind-wave mixing, and the regime of hydrological characteristics of the reservoir. The situation with methane fluxes distribution between the observed years differs a lot. Further continuation of work at the selected facility, improvement of fieldwork methods and laboratory experiments will be aimed at improving scientific knowledge in the field of studying methane emissions from water bodies. Also, this study can help in assessing the contribution of reservoirs to the global methane emission from the earth's surface.

The authors of this article thank the Scientific Base of MSU "Krasnovidovo" for helping with science equipment and providing place for research. Also, the authors would like to thank the researchers from Institute of Atmosphere Physics Russian Academy of Science for helping with sampling and laboratory analyzes.

\section{References}

1. Forster, P., V. Ramaswamy, P. Artaxo, et. al., Changes in atmospheric constituents and in Radiative Forcing (Asses. Report of the IPCC Cambridge University Press, Cambridge 2007)

2. Tortajada C., Altinbilek D., Biswas K. Impact of large dams: A Global Assessment (Water Recourses Development and Management, Berlin 2012)

3. Tremblay A., Roehm C., Varfalvy L., Garneau M. Greenhouse Gas Emissions - Fluxes and Processes (Springer, Berlin 2005)

4. Deemer B.D., Harrison J.A., Li S., Beaulieu J., Delsontro T., Barros N. Jose F D. et.al. BioScience. 66. № 11, 949 (2016)

5. Bastviken D., Santoro A., Marotta H. et. al. Environ. Sci. Technol. 44, 5450 (2010)

6. K. Edelshtein, Hydrology of lakes and reservoirs ("Pero" press, Moscow 2014)

7. Gash J., Goldenfum J., Richard M. Taylor et.al. The World Bank Contract 7150219 Greenhouse gas emissions related to freshwater reservoirs (2010) 